\title{
Trends of Moisture and Electrical Conductivity in Clay Liners
}

\author{
Muawia Dafalla $(\mathbb{D}$, Ahmed Al-Mahbashi, and Mosleh Al-Shamrani \\ Bugshan Research Chair in Expansive Soils, Civil Engineering, King Saud University, Riyadh, Saudi Arabia \\ Correspondence should be addressed to Muawia Dafalla; mdafalla@ksu.edu.sa
}

Received 29 March 2018; Accepted 27 June 2018; Published 1 August 2018

Academic Editor: Micol Todesco

Copyright ( 2018 Muawia Dafalla et al. This is an open access article distributed under the Creative Commons Attribution License, which permits unrestricted use, distribution, and reproduction in any medium, provided the original work is properly cited.

\begin{abstract}
This research is aimed at investigating the influence of ambient air temperature on the moisture content and electrical conductivity of clay sand mixtures. Volume changes as a result of shrinking or swelling are very much related to the moisture content and the electrical conductivity for liners consisting of sand and clays. The laboratory tests carried out for clay sand mixtures subjected to drying indicated a bilinear trend for 15, 20, 25, and 30\% clay content. Moisture content measurements are influenced by the ambient temperature and exposure time. Watering a clay sand layer at a regular frequency in a field site revealed useful information on the trends of moisture gain and loss. Suction fluctuation associated with these changes is responsible for absorbing variable amounts of water. Moisture/Temp/EC sensors (5TE) were utilized to survey a sand clay liner section over 30 day's period. A metrological station installed within the site was used to observe temperature, humidity, and rain fall. The drop of moisture and electrical conductivity was found to be nonlinear with temperature changes and reflecting the bimodal nature of the soil. The general trends of repeated wetting and drying were found similar in shape.
\end{abstract}

\section{Introduction}

Clay liners are barriers consisting of natural earth materials. They are used alone or as a part of an environmental system to control the movement of fluids to and from a specific earth zone to protect against pollution and contamination. They are also referred to as clay sand liners due to the sand used as a dominant constituent of the liner mixture.

Introduction of moisture and electrical conductivity sensors made observations on soil moisture interactions a more convenient approach and helped researchers, geotechnical engineers, and landscape industries to predict soil behavior when subjected to wetting and drying. Automatic irrigation pumps can be triggered when the soil is desiccated or when water is not enough for plants. Environmental engineers can also benefit from the information provided by these sensors when used in clay sand liners. This study focuses on the trends of moisture and electrical conductivity changes in clay sand mixtures used in liners. This study provides a comparison of the moisture trends and electrical conductivity for mixtures drying under room temperature and clay sand mixtures drying in the field. It also highlights the differences between gravimetric and volumetric moisture content. The sensors predict the moisture content based on electrical conductivity measurements. These are greatly influenced by the clay mineralogy and water chemistry. A calibration factor shall always be considered in order to obtain relevant data.

Another concern for geotechnical engineers is the volume change associated with expansive or highly plastic soils. The clay can swell and shrink when subjected to moisture changes, and this can affect the volumetric measurements. The drying out of clay sand mixtures leads to reduction in volume until sand grains get into contact or when the clay reaches its shrinkage limit.

Conductivity is an inverse parameter of electrical resistivity. Topp et al. [1] claimed that the dielectric constant, at frequencies in the range $1 \mathrm{MHz}$ to $1 \mathrm{GHz}$, depends on the volumetric water content and can be determined empirically. The dielectric constant is measured using time-domain reflectometry commonly referred to as (TDR). Higher electrical conductivity is associated with moist soils, and this is presented by many researchers $[2,3]$. Unsaturated soils include three phases: solid, air, and water. Friedman [4] stated that for apparent electrical conductivity, the only 
TABle 1: Physical properties of Al-Qatif clay.

\begin{tabular}{lc}
\hline Property & Range \\
\hline Material passing sieve number 200 (\%) & $>90$ \\
Liquid limit (\%) & $130-150$ \\
Plastic limit (\%) & $60-70$ \\
Plasticity index (\%) & $70-80$ \\
Maximum dry density $\left(\mathrm{kN} / \mathrm{m}^{3}\right)$ & $11.5-12.0$ \\
Optimum moisture content $(\%)$ & $32-40$ \\
Swell percent (ASTM D4546) (\%) & $16-18$ \\
Swelling pressure (ASTM D4546) at & $500-800$ \\
a density of $12.0 \mathrm{kN} / \mathrm{m}^{3}\left(\mathrm{kN} / \mathrm{m}^{3}\right)$ & \\
\hline
\end{tabular}

conducting phase is the aqueous solution. This paved the way for using it in evaluating the volumetric water contents $(\theta)$.

However, there are many factors that can influence the determination of the electric conductivity including soil density, porosity, particle shape and orientation, cation composition, and temperature. An increase in temperature results in a decrease in soil electrical resistivity. Electrical conductivity measurement trends can be defined and established for particular soil mixes, but it may remain site-specific and calibration for each soil will help provide quality data. This study is aimed at investigating moisture and electrical conductivity of sand clay mixtures in the laboratory and field at varying temperatures. The sand clay mixtures were prepared at densities and packing state similar to what is normally accepted in liner construction and practice.

\section{Materials and Experimental Program}

2.1. Materials Used. This study is carried out for a liner material consisting of sand clay mixtures prepared for the purpose of intercepting seeping water through granular sand along the coastal zone in Eastern Saudi Arabia.

Fine to medium sand, rounded to subrounded poorly graded material, is used in this investigation. The sand is naturally occurring and abundant in Saudi Arabia. The specific gravity of sand is 2.66 , the uniformity coefficient is 1.737 , and the curvature coefficient is 1.078. The sand is classified within the SP group (poorly graded sand) in accordance with ASTM D 2487. The clay selected for use in the liner was obtained from the city of Al-Qatif (Saudi Arabia, Eastern province). Elkady et al. [5] stated that Al-Qatif clay is highly expansive and rich in smectite minerals including montmorillonite (>50\%). Al-Qatif clay has a liquid limit of 140 and a plasticity index of 95 . It is classified as $\mathrm{CH}$ (clay with high plasticity) in accordance with the ASTM D 2487 [6]. In order to prepare the liner material, Al-Qatif clay was air-dried, pulverized, and sieved through a sieve size of 425 micrometers. The sand and clay were mixed thoroughly until a uniform distribution is dominant over the whole mix.

Table 1 presents physical properties of Al-Qatif clay. The swelling parameters were measured in accordance with ASTM D4546 [7].

2.2. Laboratory Experiments. Sand clay mixtures were prepared in the laboratory for clay contents of $15,20,25$, and
$30 \%$. The compaction tests were carried out in accordance with ASTM D698-method A. The molding conditions for clay sand mixtures are as follows: the $15 \%$ clay is prepared at $15.2 \%$ moisture content and $18.1 \mathrm{kN} / \mathrm{m}^{3}$ dry density. The $20 \%$ clay is prepared at a moisture content of $15 \%$ and a density of $18.6 \mathrm{kN} / \mathrm{m}^{3}$. The $25 \%$ clay is prepared at $15.5 \%$ moisture content and $18.3 \mathrm{kN} / \mathrm{m}^{3}$ dry density, and the $30 \%$ clay is prepared at 13.7 moisture and $18.4 \mathrm{kN} / \mathrm{m}^{3}$ dry density. All these parameters are related to the compaction properties of the mixtures. The moulds used were cylindrical with $60 \mathrm{~mm}$ height and $71 \mathrm{~mm}$ diameter. 5TE moisture/Temp/ EC sensors were attached to each sample and connected to data loggers capable of recording data intervals of one hour. In order to measure the gravimetric water content, a balance was used to measure the weight of sample at variable time intervals. Profiles for volumetric water content and electric conductivity as given by the sensor were reported. The balance data were used to calculate gravimetric water content and actual volumetric water content.

The sample was left to dry out under room temperature which ranged from $22^{\circ} \mathrm{C}$ to $22.5^{\circ} \mathrm{C}$ degrees Celsius. Balance weights were taken continuously until no further reduction in sample weight is observed.

2.3. Field Section Experiment. A field section experiment was constructed on site in order to test a clay sand liner under natural weather conditions of varying temperature and moisture. A weather station was installed to monitor temperature, rainfall, wind, and other parameters. The field section was selected to represent typical layering proposed for use in this site. The field section was of dimensions $200 \mathrm{~cm} \times 100 \mathrm{~cm} \times 50 \mathrm{~cm}$. The liner thickness is $10 \mathrm{~cm}$ compacted to the maximum dry density and optimum moisture content. The clay sand liner is underlain by a drainage layer and overlain by sand and agricultural soil as indicated in the schematic diagram shown in Figure 1 which presents the general soil profile and view of the as-constructed section covered by grass and installed with monitoring equipment. The clay content of the clay sand liner is $20 \%$. Wetting or irrigation conditions were kept identical for all wetting cycles. The liner layer is fitted with two 5TE Decagon sensors connected to Em50 data loggers. The sensors were set to record the electrical conductivity, volumetric water content, and temperature at one-hour interval.

Finally, the matric suction versus water content profile was measured in the laboratory for sand-clay mixture (15\% clay) over a wide range using combination of axis translation technique and filter paper technique as per ASTM D6836 (2002) and ASTM D5298 [8].

\section{Results and Discussion}

3.1. Laboratory Investigations. The direct measurement of moisture content either gravimetric or volumetric is a conventional approach. The procedure may not be practical if the moisture profile is needed for an extended period of time. Figure 2(a) presents a plot of moisture content versus time for four clay sand mixtures prepared at 15, 20, 25, and $30 \%$ clay content. The moisture is determined using 


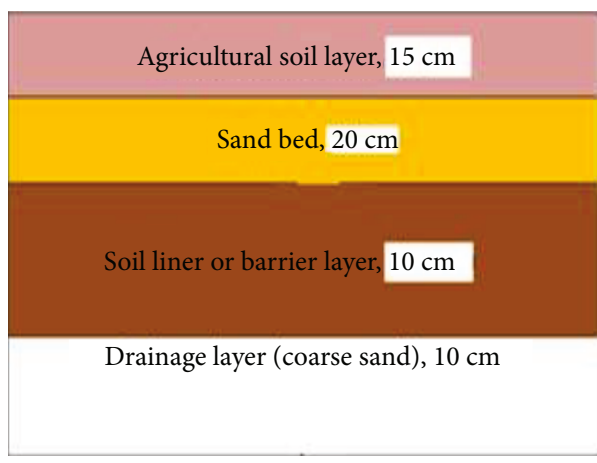

(a)

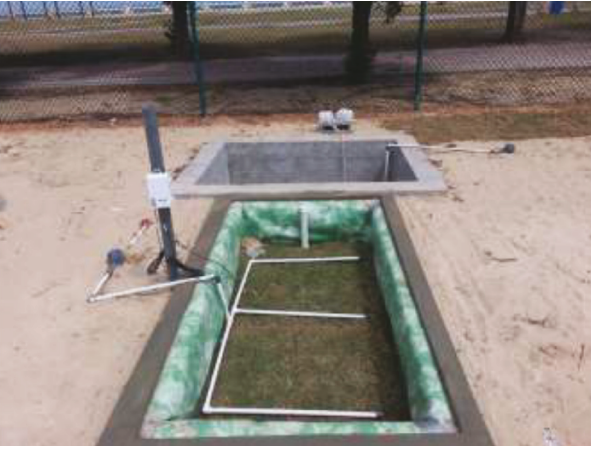

(b)

Figure 1: (a) Typical field section profile and (b) section view.

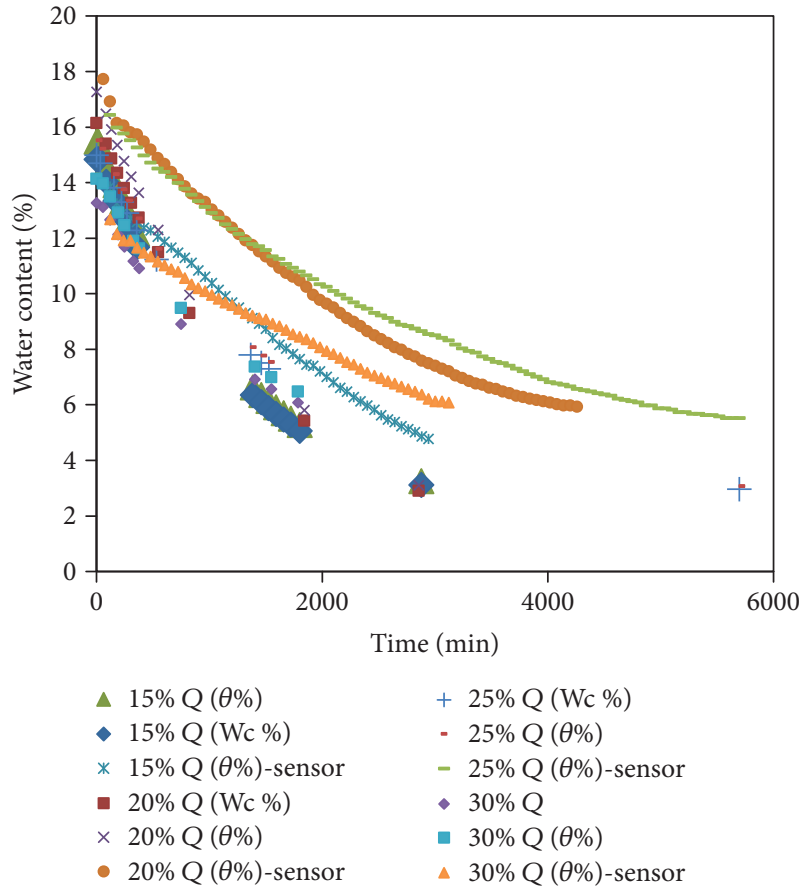

(a)

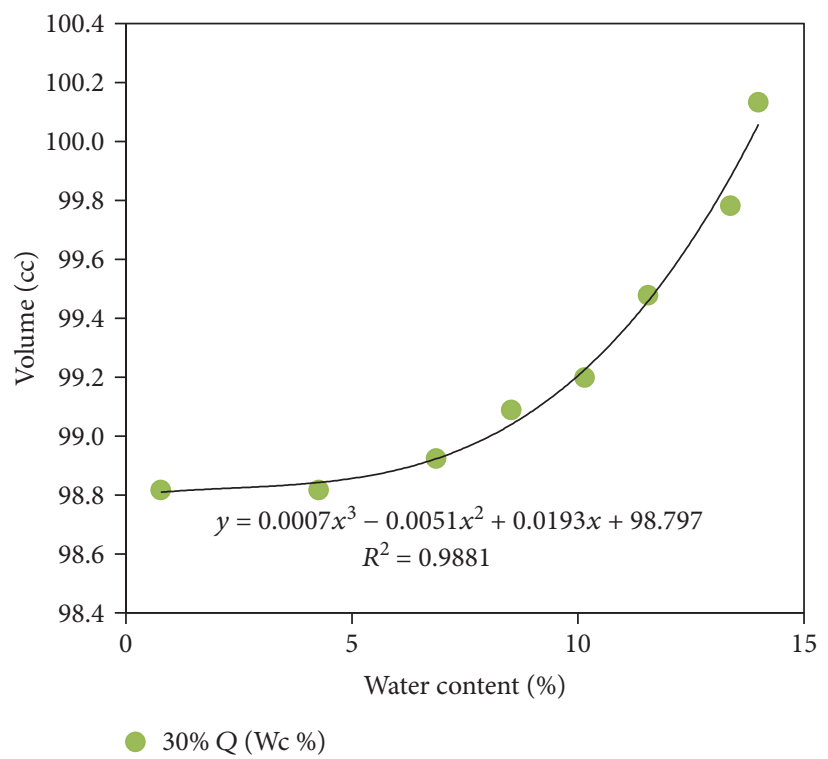

(b)

FIgure 2: (a) Moisture as measured using three different methods for a range of clay content. (b) Volume changes for $30 \%$ clay mixture at variable moisture content.

a conventional approach for both gravimetric indicated as $(\mathrm{Wc} \%)$ and volumetric indicated as $(\theta \%)$. The sensor 5TE readings give the volumetric moisture content for clays as designed and calibrated by the manufacturing company. Figure 2(b) indicates trends of volume change for 30\% clay observed at variable moisture content. The gradient is significantly changed below $7 \%$ moisture content. In order to assess volume changes in the sample during the process of drying, computations were performed.

The desiccation within the first 5 to 10 hours showed two different trends and can be approximated to a bilinear plot as shown in Figure 3(a). The differences between the gravimetric and volumetric moisture content is not high for this particular clay. The sensor readings indicate a shift which can be assumed constant after an initial period of 3 to 4 hours. The bilinear nature of the curve is a sign of two different desiccation mechanisms, and this is likely related to the clay chemistry. The soil water characteristic curve which plots moisture versus suction indicates drying trends which can be either unimodal or bimodal. Elkady et al. [5] stated that the air entry value and residual water content were observed to increase with the increase in clay content signifying an increase in water retention capacity. They suggested that the bimodal form of the SWCC indicates the presence of two levels of pore sizes, namely, macropores and mesopores/micropores.

The sensor reading profile is a smooth curve but can be broken down to two distinct zones. The magnitude of the 


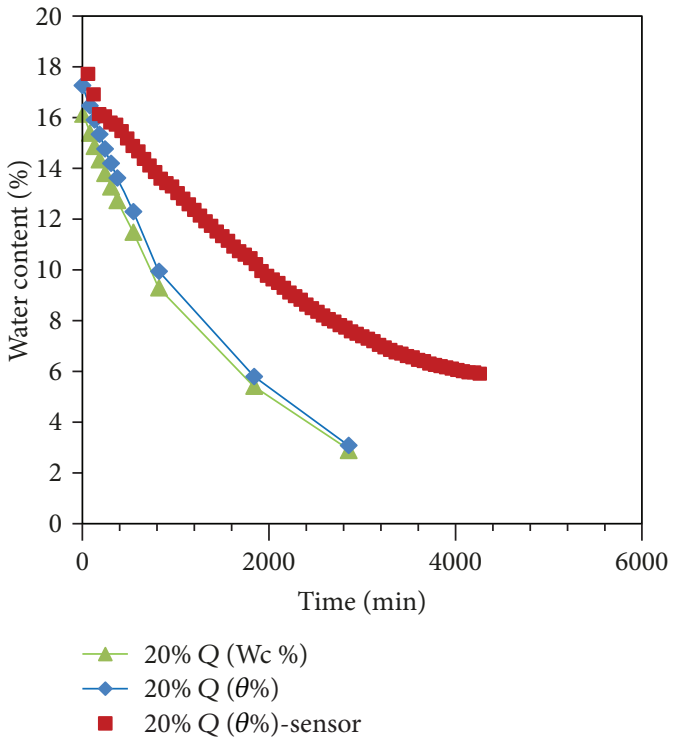

(a)

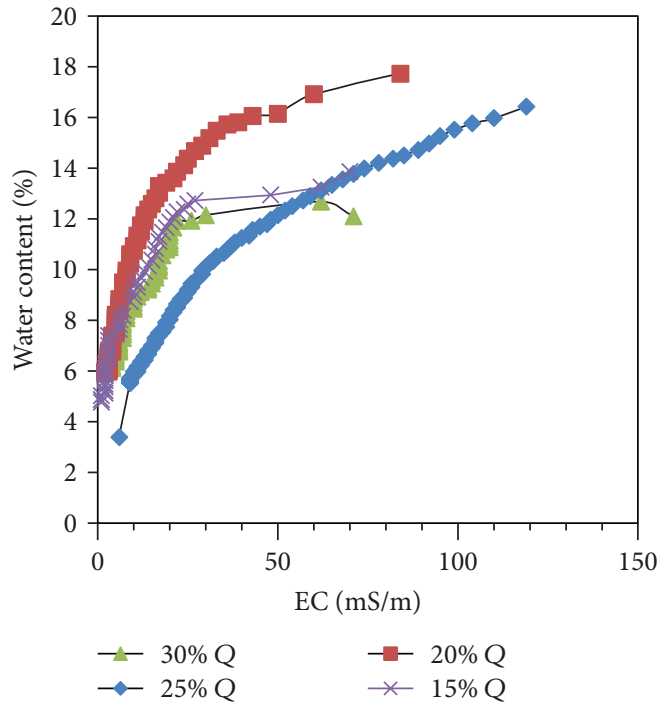

(b)

Figure 3: (a) Moisture measurements for 20\% clay mixture. (b) Electrical conductivity measurements for four different clay mixtures.

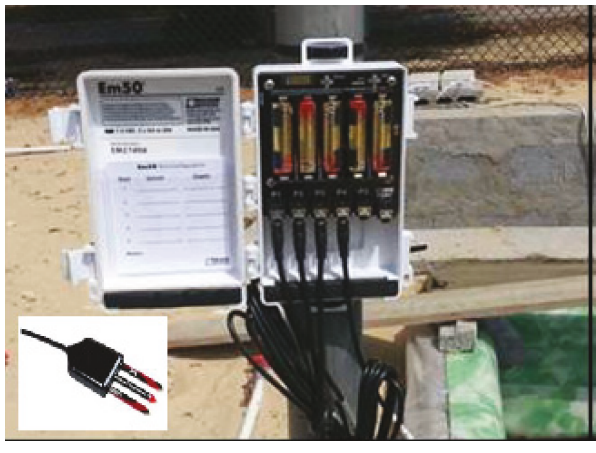

(a)

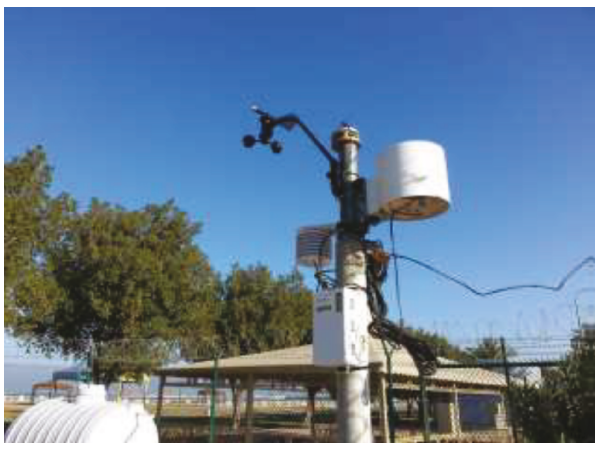

(b)

FIGURE 4: (a) Em50 data logger for 5TE sensors and (b) a weather station constructed on site.

shift from actual water content results is related to clay content, but it appears that other factors contribute to this shift. Packing state, clay chemistry, and interparticle repulsion and attraction forces may have a role in determining the level of this shift. However, calibration of sensors to clays in general may not be accurate. Sensor manufactures may give some reliability ranges, but these must be verified and supported by site-specific conditions. Trends of electrical conductivity are shown in Figure 3(b).

3.2. Field Section. Figures 4(a) and 4(b) shows field equipment used. For a field section of $20 \%$ clay liner constructed on site and observed over 30 days, the data for moisture content and electrical conductivity tests are presented in Figures 5 and 6.

This study is focused on the changes and trends of water content and electrical conductivity of clay sand liners under varying ambient temperatures and repeated cycles of wetting and drying. The soil suction is related to the moisture content and saturation. The suction tends to be zero when a soil layer is fully saturated. On increase of the surrounding temperature or drying, suction builds up and moisture content is driven below saturation until all free water is removed. Swell and shrink in soil volume accompany these wetting and drying cycles. How does the water content build up when the clay is initially dry? In fact, the term dry is a very loose term without introducing the suction value of the layer. High suction attracts water at a higher speed and short period while low suction requires time to absorb water and the hydraulic conductivity is relatively low.

Day and night variation creates a zigzag, but the temperature is increasing from day one to day 30 during the period from March 20 to April 20 of 2014. The temperature variation during the day is likely affecting the drying process. The slope, moisture versus time appears similar for all cycles except for the 7 th watering cycle due to the extended drying period. More water is absorbed when the clay is subjected to higher temperature.

The wetting or the maximum moisture content is achieved in about a 2- to 3-hour period, and the water content started to drop slowly for the clay sand liner of $20 \%$ Al-Qatif clay (Figure 5). 


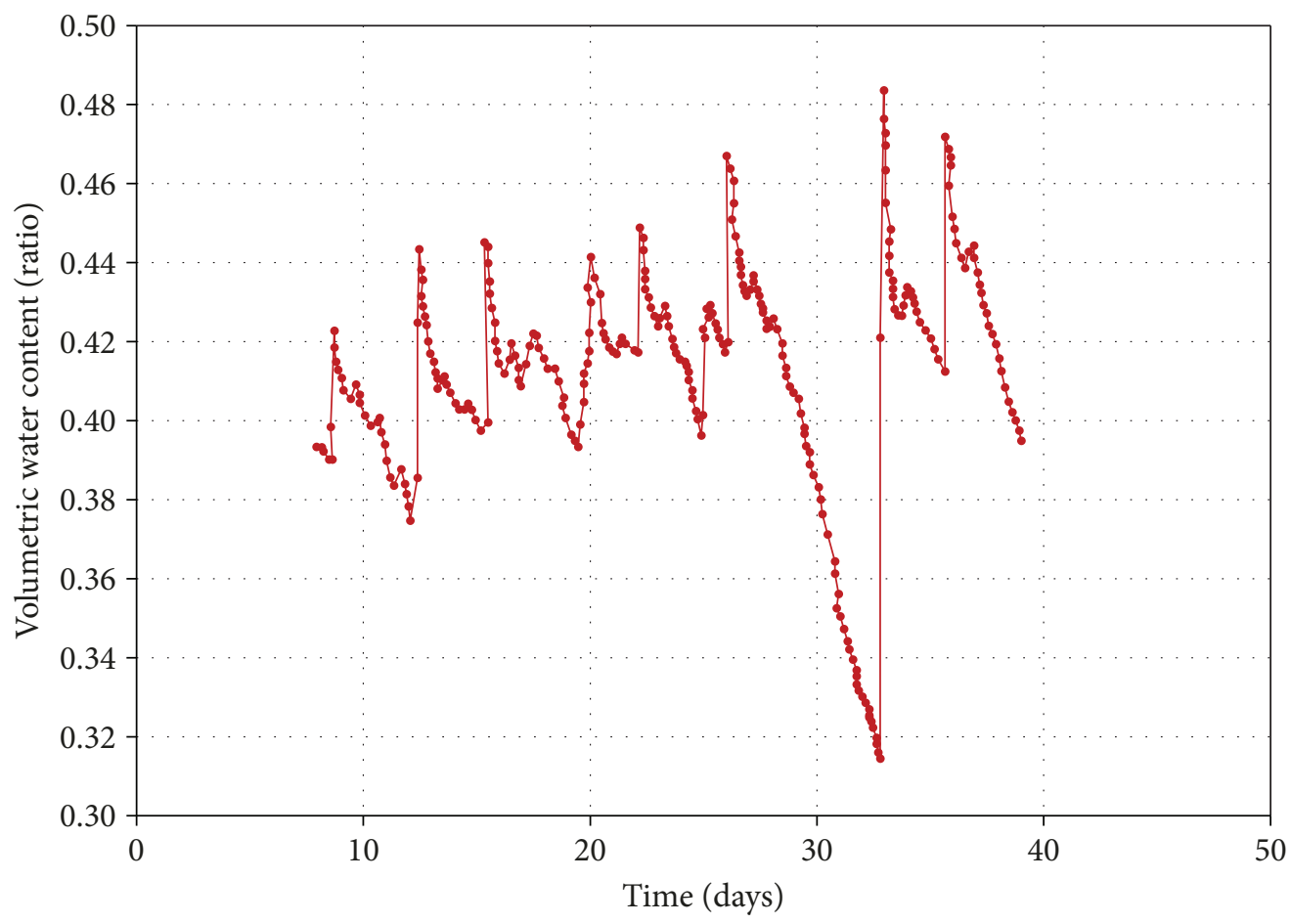

(a)

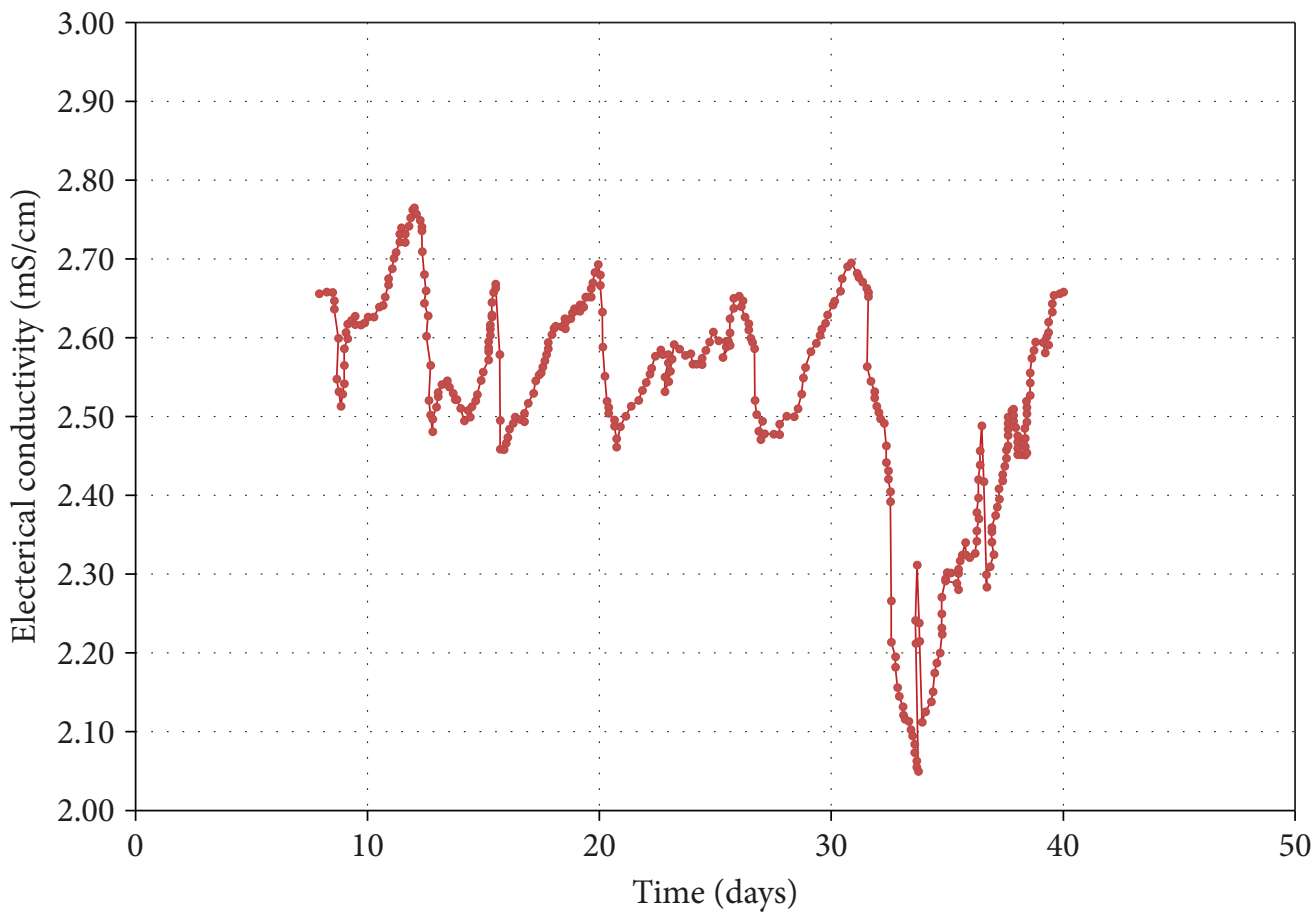

(b)

Figure 5: (a) Moisture profile over 30 days and (b) electrical conductivity profile over 30 days.

The field ambient temperature profile over 30 days' period as shown in Figure 6(a) indicates an increase in temperature in the order of 6 to 7 degrees Celsius. The plots of electrical conductivity showed repeated similar trends but with a very slight increase in magnitude during this period as observed in Figure 7(b). This is found in agreement with
Campbell et al. [9] who claimed that an increase in temperature can result in increase in electrical conductivity. The increase in salt concentration is the main driver for increasing the electrical conductivity.

The weather station did not record significant rainfall during this six-month period. 


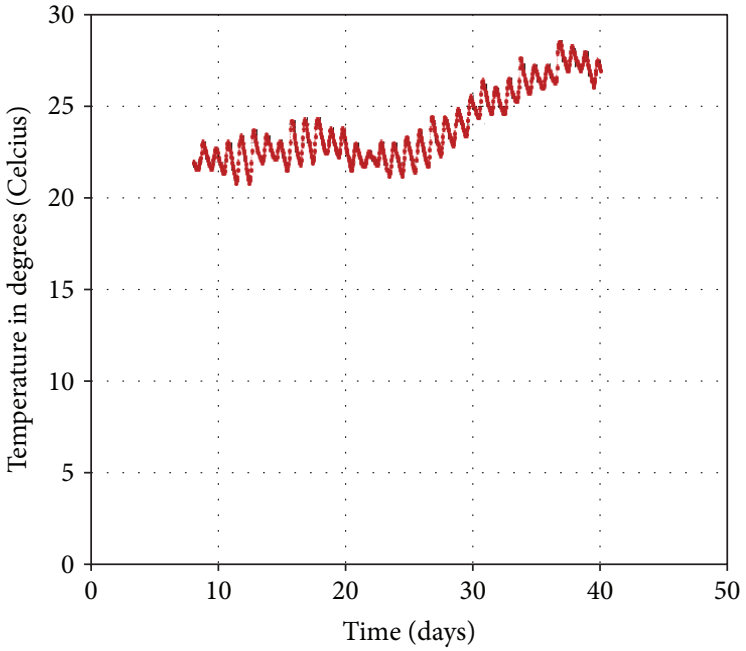

(a)

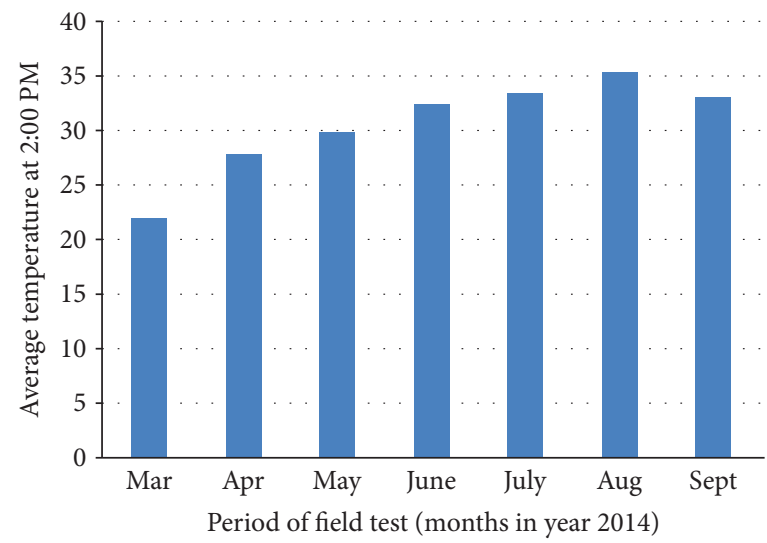

(b)

FIGURE 6: (a) 30-day temperature profile and (b) average temperature profile.

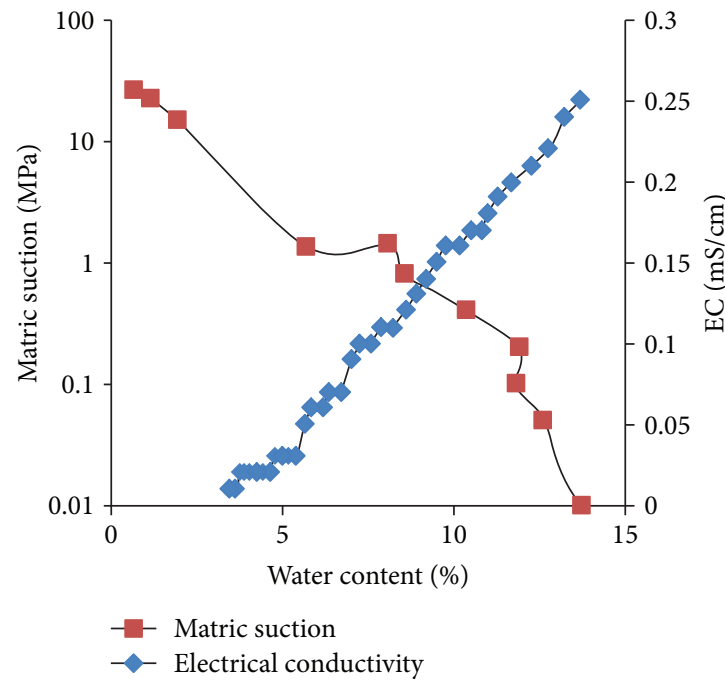

(a)

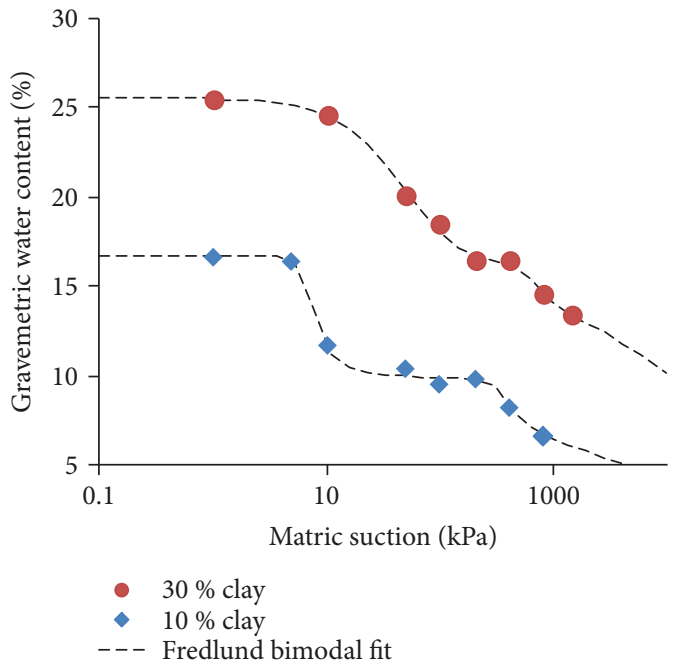

(b)

Figure 7: (a) Matric suction and electrical conductivity versus water content for 15\%-clay sand mixture. b Soil water characteristic curve of sand-clay mixture.

Establishing a prediction curve for suction level for a sand clay mixture compacted to the optimum moisture content can serve as a prediction tool for estimating hydraulic properties. The unsaturated liquid flow principle needs to be applied if a prediction of flow is required. An example graph of the SWCC for sand clay mixture of Al-Qatif clay is presented in Figures 7(a) and 7(b) [10]. This graph defines the relationship between soil suction and water content. However, this curve is not coupled with temperature variation as all tests were conducted at room temperature. The shape of the graph is bimodal where an inflection point can be seen. Future studies of SWCC at different temperatures will enable a precise prediction when more than one factor is influencing the behavior of sand clay mixtures.
3.3. Matric Suction and Electrical Conductivity. The matric suction (S) versus water content profile for a $15 \%$ claysand mixture was obtained for the entire range of suction using the combination of axis translation technique and filter paper technique. Figures 2 and 3 present graphs for moisture measurements of variable volume changes and electrical conductivity for selected mixtures. The electrical conductivity (EC) was plotted for the measured gravimetric water in Figure 7(a). Comparing the trends of matric suction versus water content and the electrical conductivity versus water content, we can observe an opposite trend for these two parameters. This plot could be used as a key tool to estimate the matric suction for the unsaturated sand-clay mixture using measurements of electrical conductivity for the zones 
below air entry value. The measurements of electrical conductivity either at field or in the laboratory are always quicker and simple.

Figure 7(a) indicates two different trends for the matric suctions: before the point of air-entry value on the suctionwater content profile and after this point. The point of airentry value is defined as the value of suction where water starts being expelled from the largest pores of soil specimen.

The correlation that could be done between matric suction and electrical conductivity were defined along these two zones (before and after air-entry value) as follows:

$$
\begin{aligned}
\ln (S, \mathrm{MPa})= & -6.024 E^{-4}(\mathrm{EC})^{2}+4.105 E-3(\mathrm{EC})+1.884 \\
& \text { for matric suction between }(1.3-14.5 \mathrm{MPa})
\end{aligned}
$$

$$
\begin{aligned}
\ln (S, \mathrm{MPa})= & -9.417 E^{-3}(\mathrm{EC})+2.558 \text { for matric suction } \\
& \text { between }(0.05-1.4 \mathrm{MPa})
\end{aligned}
$$

\section{Conclusions}

Computed gravimetric and volumetric water content measurements are ideal for a limited number of observations. The need for mapping data over an extended period of time will require the use of sensors and data loggers. The trend of moisture content on drying indicated a bilinear trend for clay sand mixtures of $15,20,25$, and $30 \%$ clay content.

The slope of moisture versus time appears similar for all cycles of wetting and drying. The maximum moisture content is achieved in a short time after watering (2- to 3-hour period for the clay sand liner with 20\% Al-Qatif clay). This time depends on suction level and mineralogy of the clay.

The drop in moisture content and electrical conductivity with time was found to be nonlinear in general and reflecting the bimodal nature of the soil. The influence of temperature variation is reflected in the magnitude of both parameters and the shape of the graph.

Introduction of moisture content trends associated with different times and temperature can be useful in assessment of clay sand liners. The profile of electrical conductivity can also assess the level of salt changes when liners are subjected to water of different chemistry.

\section{Notations}

$\theta$ : Volumetric water content

TDR: Time domain reflectometry

T: $\quad$ Temperature

SP: Class of soil of poor gradation

S: $\quad$ Matric suction

EC: $\quad$ Electric conductivity measured in $\mathrm{mS} / \mathrm{m}$

E: $\quad$ Elastic modulus of the reinforcement.

\section{Data Availability}

The data used to support the findings of this study are available from the corresponding author upon request.

\section{Conflicts of Interest}

The authors declare that they have no conflicts of interest.

\section{Acknowledgments}

The authors extend their appreciation to the Deanship of Scientific Research at King Saud University for funding this work through the Research Chair Program of King Saud University.

\section{References}

[1] G. C. Topp, J. L. Davis, and A. P. Annan, "Electromagnetic determination of soil water content: measurements in coaxial transmission lines," Water Resources Research, vol. 16, no. 3, pp. 574-582, 1980.

[2] Q. Y. Zhou, J. Shimada, and A. Sato, "Three-dimensional spatial and temporal monitoring of soil water content using electrical resistivity tomography," Water Resources Research, vol. 37, no. 2, pp. 273-285, 2001.

[3] A. Binley, G. Cassiani, R. Middleton, and P. Winship, "Vadose zone flow model parameterisation using cross-borehole radar and resistivity imaging," Journal of Hydrology, vol. 267, no. 3-4, pp. 147-159, 2002.

[4] S. P. Friedman, "Soil properties influencing apparent electrical conductivity: a review," Computers and Electronics in Agriculture, vol. 46, no. 1-3, pp. 45-70, 2005.

[5] T. Y. Elkady, M. A. Dafalla, A. M. Al-Mahbashi, and M. A. Al-Shamrani, "Evaluation of soil water characteristic curves of sand-clay mixtures," International Journal of Geomate, vol. 4, no. 2, pp. 528-532, 2013.

[6] ASTM (American Society for Testing Materials), Standard Practice 374 for Classification of Soils for Engineering Purposes (Unified Soil 375 Classification System), ASTM D2487-11, ASTM International, West 376, Conshohocken, PA, USA, 2011, http://www.astm.org.

[7] ASTM D4546, Standard Test Methods for One-Dimensional Swell or Collapse of Cohesive Soils, vol. 4.08, ASTM International, West Conshohocken, PA, USA, 2003, D-18 Committee on soils and rocks.

[8] ASTM (American Society for Testing Materials), ASTM D5298-16, Standard Test Method for Measurement of Soil Potential (Suction) Using Filter Paper, ASTM International, West Conshohocken, PA, USA, 2016, http://www.astm.org.

[9] R. B. Campbell, C. A. Bower, and L. A. Richards, "Change of electrical conductivity with temperature and the relation of osmotic pressure to electrical conductivity and ion concentration for soil extracts," Soil Science Society of America Proceedings, vol. 13, pp. 66-69, 1948.

[10] ASTM (American Society for Testing Materials), Standard Test 368. Methods for Determination of the Soil Water Characteristic Curve for 369 Desorption Using a Hanging Column, Pressure Extractor, Chilled Mirror 370 Hygrometer, and/or Centrifuge, ASTM D6836- 02(2008)e2. ASTM 371 International, 2008. 

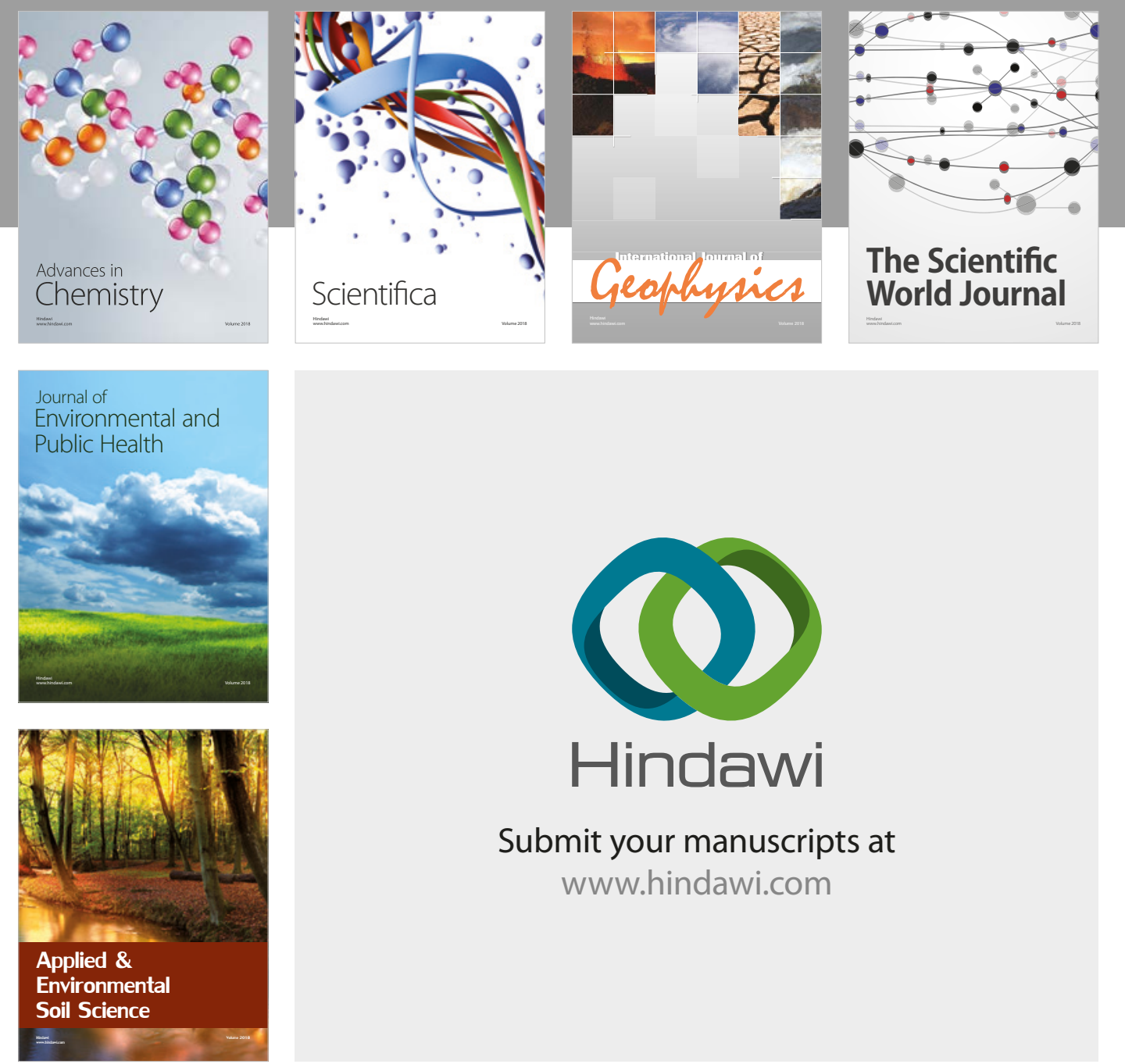

The Scientific

\section{World Journal}
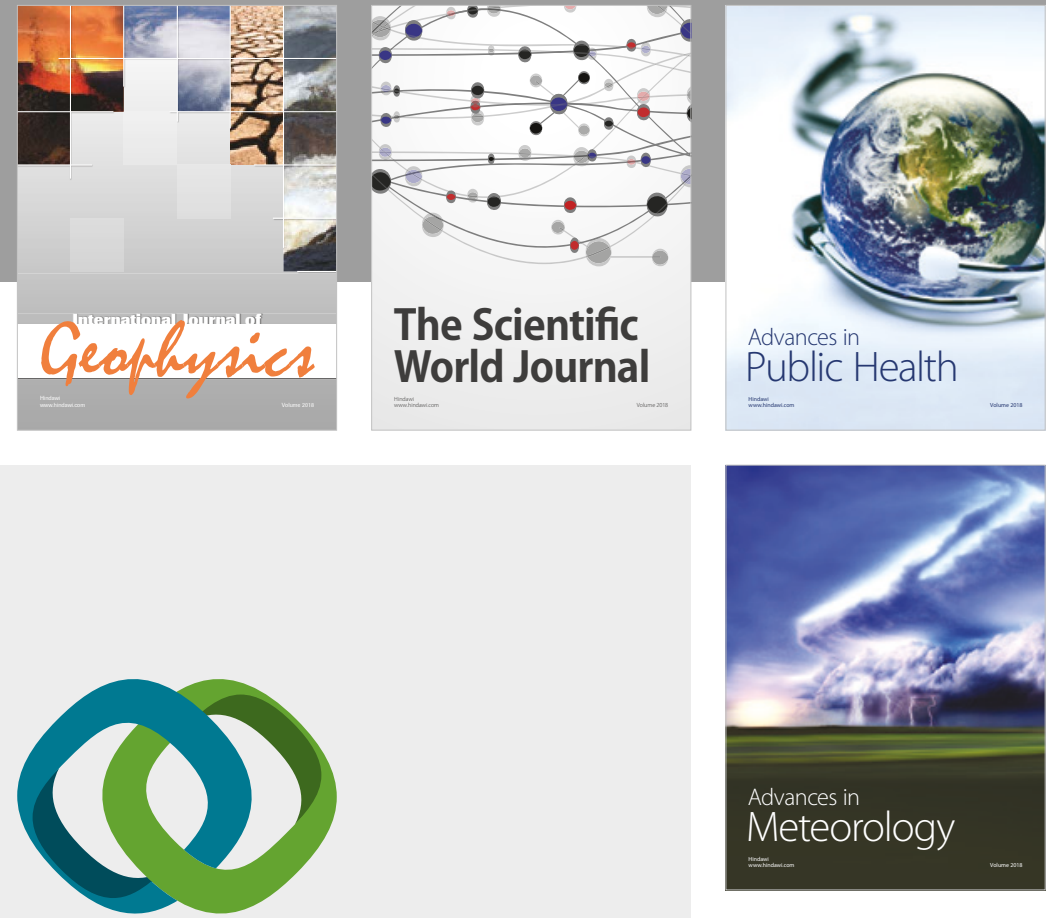

Advan

Public Health

\section{Hindawi}

Submit your manuscripts at

www.hindawi.com
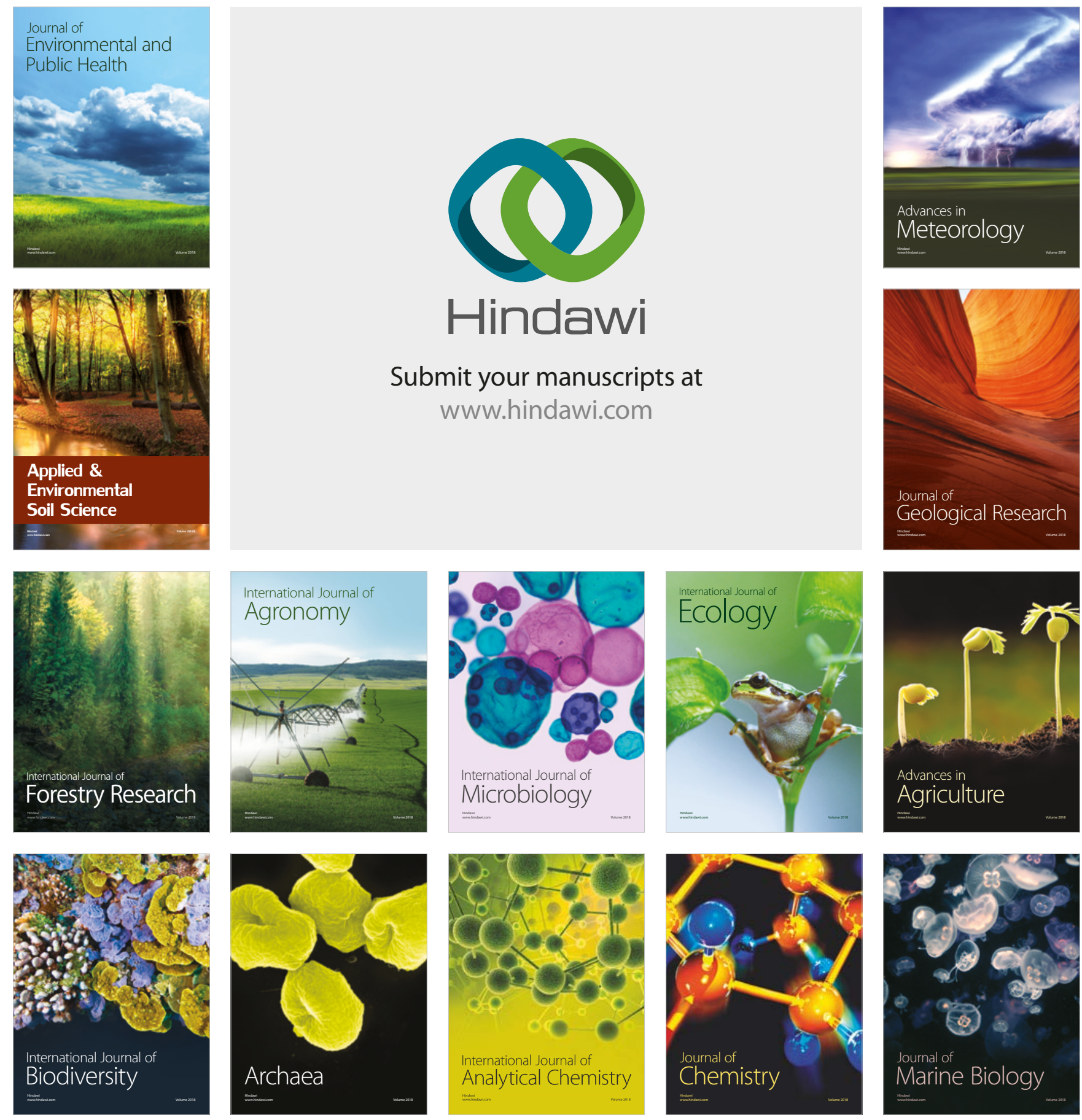